\title{
Creating knowledge management skills in primary care residents: a description of a new pathway to evidence-based practice in the community
}

For several years, I have coordinated a critical appraisal course for residents. Participants, who were organised initially as a traditional journal club, would gather weekly and review an important research paper that either had recently been published or had been found during a Medline search while attempting to answer a question that arose during clinic. The housestaff consistently rated the course highly and appeared to be happy with it. When I ran into them after they were in practice, however, they would frequently reminisce fondly about "the days when we had time to read journals."

As for many educational interventions during residency, the traditional journal club seemed appropriate but unfortunately did not fit with "real world" practice. Several major factors influence the uptake of the practice of evidence-based medicine in primary care, including time constraints and the volume of clinical literature. ${ }^{1-4}$ However, several recent developments have made tackling these obstacles possible: high quality preappraised evidence resources; multi-intervention continuing education models that fit the learners' needs, setting, and social environment; and improved technology that makes delivering knowledge to the point of care possible.

After considering these factors, I arrived at a conclusion similar to that of other evidence-based medicine proponents, ${ }^{5}-$ that evidence-based clinicians of the future may not need to be experts in clinical epidemiology but instead could manage with several high quality knowledge products. This realisation led to the creation of a new educational intervention for residents that would enable them to develop:

- basic skills in assessing the quality and relevance of information

- knowledge of high quality distillation services that they can use in a typical community practice

- skills to use new technologies (handheld computers or the Internet) to access data at the point of care

- skills in adapting the evidence to fit the needs of patients

- skills in assessing and overcoming barriers to evidencebased medicine that are so frequent in primary care.

This new course has several components and begins with an introduction to critical appraisal that is held during residents' first month of training. During this 1 hour session, the discussion focuses on assessing the quality and relevance of research and provides an opportunity to introduce residents to the "Users' Guides to the Medical Literature." ${ }^{6}$ A subsequent session addresses the topic of paper and web based pathways to relevant, high quality evidence. We highlight various resources by using our primary care evidence-based medicine web site (on http://dfcm19.med.utoronto.ca/twhdfcm/home.htm) and provide residents with a tour of some of these resources.

On 3 subsequent occasions during the year, residents rotate onto our service in groups of 4 for a 1 month period. Each month, 2 residents are assigned to be facilitators for the evidence-based medicine sessions, and they select a clinical topic to be addressed during these sessions. The facilitators do web and handsearches of available resources and identify the resources to be reviewed by the group. Typically, the sessions follow this format:

- Week 1: practice-based small group module. This is a continuing medical education (CME) initiative that is case based and includes a high quality summary of the evidence. It replicates small group sessions that have developed across Canada during which participants meet locally with 1 member trained as a facilitator. Participants learn to interpret the evidence and are prompted to apply it to "real world" patients. The residents model these sessions during their rotation and can continue such activity when they begin to practice in the community.

- Week 2: review of a clinical practice guideline. Because evidence is frequently packaged for primary care clinicians as clinical practice guidelines, we believe that residents should become familiar with appraising and using them. During this session, residents learn how to interpret guidelines and how to determine areas in which questions remain.

- Week 3: journal club. Frequently, additional clinical questions arise during weeks 1 and 2. This session is used to complete a critical assessment of a specific research report that might answer them.

- Week 4: "core day." All residents attend this session, and the resident facilitators are given 15 minutes to disseminate a "toolkit" they have developed to make it easier to achieve best practice in a particular clinical area. The goal is to develop a resource that can be perused and applied to clinical practice within 1 minute. Toolkits must have 2 components: firstly, a narrative outlining the clinical bottom line, things not to miss, an answer from a relevant clinical practice guideline, treatment options, what we don't know, and pearls; secondly, any relevant practice aids, such as algorithms, drug information, abstracts, flow sheets, and patient handouts. We emphasise brevity, attractive graphics, and answers to our clinical questions in the creation of these toolkits. The narrative portion of the toolkit is then loaded onto handheld computers and made available to all the residents. We are in the process of developing a web version of the toolkits that we hope will enhance dissemination and implementation.

- Week 5: optional and occasional. This session is used to review a new "hot" article or piece of information and is also organised by the facilitating residents.

This course has several features that we believe are essential to promote adult learning. It is multidimensional ${ }^{78}$; uses small group learning, technology, knowledge of barriers, and several 
information sources; and is largely run by the residents. This course uses some of the skill sets paramount to traditional evidence-based medicine teaching but also incorporates the learners' needs (clinical practice guidelines and toolkits) and technology (the internet and handheld computers) and attempts to overcome barriers to practising evidence-based medicine by using toolkits.

The course is still in its infancy. It is intended to be an innovative, educational intervention that will help primary care practitioners to become evidence-based knowledge managers as they move to community practice. We are currently attempting to evaluate the effect of this course on residents' knowledge, attitudes, and behaviours. We completed pretest evaluations of our first groups of residents and are initiating post testing now that they have finished their first training year. We plan to continue to refine this course based on the residents' feedback.

MICHAEL EVANS, MD

University of Toronto Toronto, Ontario, Canada

1 Gray JA. Where's the chief knowledge officer? To manage the most precious resource of all [editorial]. BMJ 1998;317:832.
2 Sackett DL, Straus SE, Richardson WS, et al. Evidence-based medicine: how to practise and teach EBM. Second edition. Edinburgh: Churchill Livingstone; 2000.

3 McColl A, Smith H, White P, et al. General practitioner's perceptions of the route to evidence based medicine: a questionnaire survey. BMJ 1998;316:361-5.

4 Allery LA, Owen PA, Robling MR. Why general practitioners and consultants change their clinical practice: a critical incident study. BMJ 1997;314:870-4.

5 Guyatt GH, Meade MO, Jaeschke RZ, et al. Practitioners of evidence based care. Not all clinicians need to appraise evidence from scratch but all need some skills. BMJ 2000;320:954-5.

6 Oxman AD, Sackett DL, Guyatt GH. Users' guides to the medical literature. I. How to get started. JAMA 1993;270:2093-5.

7 Davis DA, Thomson MA, Oxman AD, et al. Changing physician performance. A systematic review of the effect of continuing medical education strategies. JAMA 1995;274:7005.

8 Davis D, O'Brien MA, Freemantle N, et al. Impact of formal continuing medical education: do conferences, workshops, rounds, and other traditional continuing education activities change physician behavior or health care outcomes? JAMA 1999;282:867-74. I would like to thank Anita Lambert-Lanning (our librarian who developed and
maintains our web site), Dr Peter Zia (my coteacher), Dr Phil Ellison (my chief), and of course, the residents, for their support 